\title{
A New Approach to Analysing the Body Posture of the Male Subjects
}

\author{
Manuela Avadanei \\ Faculty of Industrial Design and Business Management \\ "Gheorghe Asachi" Technical University \\ Iasi, Romania
}

\begin{abstract}
Since the beginning of civilisation, the shape of the human body has been continuously changing due to economic, social, or geographical factors, personal or social activities, habits, nutrition, lifestyle, etc.

The specialists in the field of anthropometry have reached the following conclusion: it is possible to observe the population from a country or region in order to determine the extent of its evolution between generations, evaluate the health of its individuals and to decide which characteristics need to be further monitored so that future health problems can be avoided.

Anthropometry studies are also useful for the clothing industry because they offer information about the customer. It is quite challenging to satisfy the existent wide variety of customer requests/ needs. However, a company with well-trained employees, equipped with modern IT technology and 3D software, can produce a wide variety of models and goods, perfectly adapted to the demands of the market.

Besides knowing the exact values of the customer's dimensions, the designer should also to be able to identify some peculiarities of the person body, proportions, conformation, posture, asymmetries, etc. In this way, the designer will be able to decide what characteristics of the customer's body he can underline and to choose the ones to be kept out of sight.

This paper presents the results of an anthropometric survey about body posture (the upper part of the trunk) of the male adult population. This parameter is used to describe the shape of the upper part of the trunk, an important area for garments supported on shoulders. Even if the other dimensions of the human body are invariable among the subjects of the study, the information about the diversity of body postures is useful in designing patterns of well-fit fashionable garments, individual protective garments, or performance sport garments. By using special functions of CAD systems that allow customisations, these parameters can be used in the design process, in order to optimise the shape of the garment piece and to ensure its quality.
\end{abstract}

Keywords: Male human body, anthropometric dimensions, posture parameter, balance, dimensional correspondence.

\section{INTRODUCTION}

In both every day and work life, every adult person needs to possess different types of personal belongings or items, either as a necessity or in order to accomplish various tasks. They seek to purchase products that fit their personality, lifestyle, needs, purposes, profession, level of education, social status, financial resources, etc.

The industry of apparel goods is very competitive. The producers have to conquer the market, to build a special loyalty relationship with the customer, to deal with other competitors, to adapt their technology to the newest solutions, and to stay informed about the trends and the market requirements. If the producer understands all of these aspects and adapts the products to the demands of the market, they will be successful.

In our society, fashion "dictates" new trends, define personalities and establishes new values. For the garment industry, fashion brings among trends, materials and colours, new styles, symbols, class and culture $\rightarrow$ "the latest fashion, the latest difference" [2].

It is a well-known fact that the shape and the size of a garment must fit the customer's profile regardless of whether it is an haute- couture or prêt-á-porter product.

Nowadays, digitalisation and industry 4.0 force producers to personalise and customise the prêt-á-porter products as much as possible. Besides this, the customer has the possibility to define their new model in the virtual environment (even online) by selecting the colours, materials, style, or other details (co-design process). The designers materialise the virtual model into a real one, with all the necessary features, by using their skills, knowledge and competencies, along with IT applications.

The designer must also know the dimensions of the customer's body (proportion, posture, conformation), in order to be able to design a suitable model for them.

By employing 3D special applications or software such as the 3D Body Scanner, the needed information about the human body is obtained within a few seconds, without affecting the customer's health and safety.

In this manner, the designer determines what the person looks like, which peculiarities of the human body should be concealed, and which style is advantageous for the client.

The results of the scanning process must be carefully analysed in order to determine whether the scanning process was carried out with precision and accuracy (as it is described in the scanning protocol), and if the dimensions of the human body were determined correctly. These data can be used in the customised design process of the garment patterns, provided that the CAD system can import them.

If the designer is unable to import the personal anthropometric information of the client, he will have to decide which standardised body from the CAD database or anthropometric standard is the suitable for the customer's body shape.

It is also recommended to use the available information regarding the body posture and proportions during the design process of the patterns, in order to ensure a better dimensional correspondence between the garment and the size of the body. 
This paper presents the results of an anthropometric study carried out on male subjects, focused on the analysis of the posture of the adult male body (trunk). The conclusions of this study can be used for designing and producing apparel goods that are perfectly adapted to this category of customers.

\section{WORK METHOD}

Among the morphological indicators, which are used to characterise the human shape, the posture is a very important one because it characterises the human body in a vertical position, in a static or dynamic stance.

The curves of the spine appear when the baby stands in a vertical position. During childhood, adolescence, and adulthood, the shape of the spinal column is continuously changing due to the genetical heritage, nutrition, geographical and living conditions, as well as daily activities and sports.

The posture can vary significantly from one individual to another (children, teenagers, or adults). The body postures are analysed by taking into account the shape of the trunk and the positions of the limbs.

The anthropologists analyse the posture of the trunk by considering the shape of the spinal curves and the level of the shoulder points. This is done by measuring different anthropometric distances between precise anthropometric points of the surface of the body and some planes, which are tangent to the latter. The specialised literature describes the procedure of measuring the cervical point depth (known as body posture), as well as the I and II depths at the level of the waistline. Studies in the field of anthropology and anthropometry reveal that these distances are difficult to measure and that they require well-trained personnel and adequate equipment.

Besides this, the posture of the trunk can be characterised by using other categories of anthropometric dimensions, such as length and arches. These body dimensions are easily measured with a high degree of precision, even manually or by scanning the body.

Regardless of the subject is scanned or manually measured, the whole process has to follow the anthropometric protocol (body position, clothes and measuring time) $[1,3]$.

Table 1 present the list of body dimensions, which are used in this study, and fig. 1 shows how these dimensions were measured.[5,6]

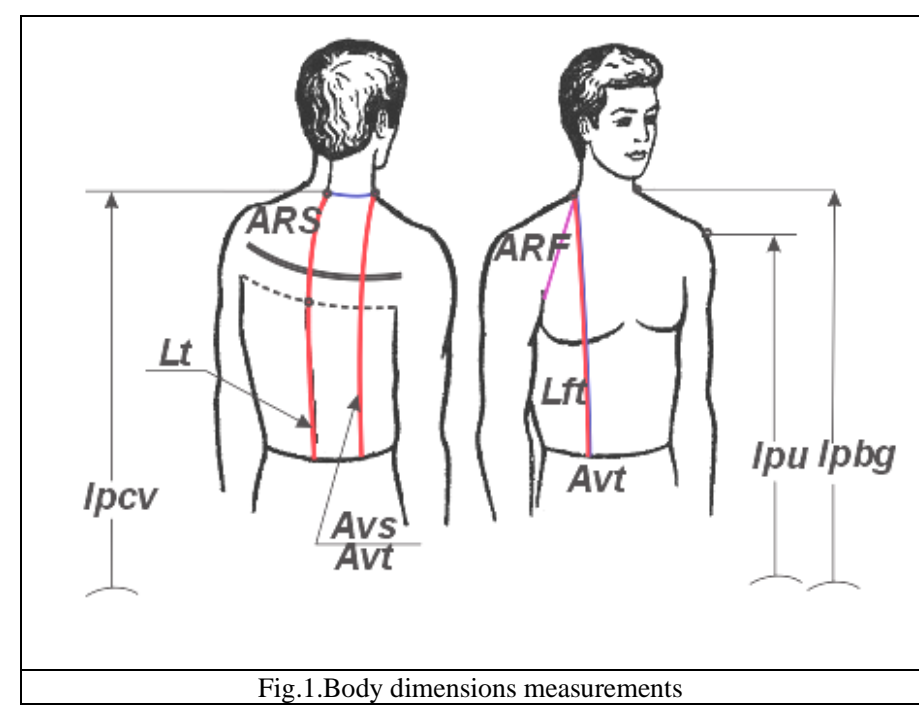

TABLE 1 . The list of body dimensions

\begin{tabular}{|c|c|c|}
\hline $\begin{array}{l}\text { The name of the } \\
\text { body dimension }\end{array}$ & Symbol & Description \\
\hline Nape to waist & $\mathrm{L}_{\mathrm{t}}$ & $\begin{array}{l}\text { The length from the cervical point to the } \\
\text { waistline, measured on the trajectory of } \\
\text { the spine }\end{array}$ \\
\hline $\begin{array}{l}\text { The length of the } \\
\text { front side of the body }\end{array}$ & $\mathrm{L}_{\mathrm{ft}}$ & $\begin{array}{l}\text { The length from the cervical point and } \\
\text { the waistline, measured vertically over } \\
\text { the neck base point and bust point. }\end{array}$ \\
\hline $\begin{array}{l}\text { The back vertical } \\
\text { arch }\end{array}$ & $\overline{A_{v s}}$ & $\begin{array}{l}\text { The length between the neck base point } \\
\text { and the waistline measured vertically } \\
\text { over the scapula point (on the backside } \\
\text { of the body). }\end{array}$ \\
\hline $\begin{array}{l}\text { The total vertical arch } \\
\text { of the trunk }\end{array}$ & $\mathrm{A}_{\mathrm{vt}}$ & $\begin{array}{l}\text { The length between the backside and } \\
\text { front side waistlines, measured } \\
\text { vertically on both the backside and the } \\
\text { front side, over the scapular point, neck } \\
\text { base point, and bust point. }\end{array}$ \\
\hline $\begin{array}{l}\text { Back armhole depth } \\
\text { considering the } \\
\text { scapula prominences }\end{array}$ & ARS & $\begin{array}{l}\text { The length between the cervical point } \\
\text { and the level of the back axillary points, } \\
\text { measured on the trajectory of the spine. } \\
\text { The measurement is made by using a } \\
\text { ruler, positioned at the level of scapula } \\
\text { points. }\end{array}$ \\
\hline $\begin{array}{l}\text { The front armhole } \\
\text { depth }\end{array}$ & $\mathrm{ARF}$ & $\begin{array}{l}\text { The length between the cervical point } \\
\text { and the axillary point of the front side } \\
\text { measured over the base neck point. }\end{array}$ \\
\hline $\begin{array}{l}\text { The height of the } \\
\text { base neck point }\end{array}$ & $\mathrm{I}_{\mathrm{pbg}}$ & $\begin{array}{l}\text { The projection of the base neck point } \\
\text { position to the ground. }\end{array}$ \\
\hline $\begin{array}{l}\text { The height of the } \\
\text { shoulder point }\end{array}$ & $\mathrm{I}_{\mathrm{pu}}$ & $\begin{array}{l}\text { The projection of the shoulder point } \\
\text { position to the ground. }\end{array}$ \\
\hline $\begin{array}{l}\text { The height of the } \\
\text { cervical point }\end{array}$ & $\mathrm{I}_{\mathrm{pcv}}$ & $\begin{array}{l}\text { The projection of the cervical point } \\
\text { position to the ground. }\end{array}$ \\
\hline $\mathrm{d}\left(\mathrm{P}_{\mathrm{cv}}-\mathrm{P}_{\mathrm{bg}}\right)$ & $\mathrm{m} 1$ & $\begin{array}{l}\text { The distance between the cervical point } \\
\text { and neck base point, measured } \\
\text { transversally. }\end{array}$ \\
\hline
\end{tabular}

The shape of the trunk can be characterized by calculating the values of the following anthropometric parameters (using the information listed in table 1):

$$
\begin{aligned}
& \mathrm{d} 1=\left(\mathrm{A}_{\mathrm{vt}}-\mathrm{A}_{\mathrm{vs}}\right)-\mathrm{L}_{\mathrm{t}} \\
& \mathrm{d} 2=\mathrm{Lft}-\mathrm{d}\left(\mathrm{P}_{\mathrm{cv}}-\mathrm{P}_{\mathrm{bg}}\right)-\mathrm{Lt} \\
& \mathrm{d} 3=[\mathrm{ARF}-\mathrm{d}(\mathrm{Pcv}-\mathrm{Pbg})]-\mathrm{ARS} \\
& \mathrm{iu}=\mathrm{I}_{\mathrm{pbg}}-\mathrm{I}_{\mathrm{pu}} \\
& \mathrm{iu} \mathrm{u}^{\prime}=\mathrm{I}_{\mathrm{pcv}}-\mathrm{I}_{\mathrm{pu}}
\end{aligned}
$$


In the first stage, a preliminary survey was carried out in order to decide upon the size of the sample. The final result is a 500 subject-sample, split into age groups (see fig.1).

The subjects included in the sample are aged between 20 and 64 years old.

This whole sample is divided into small groups by using body heights as a criterion (see table 2). These groups (listed in table 2) are defined as intervals, and the length of them is the value of the known inter-dimensional increment, established by the researchers for the adult population. [1,5].

TABLE 2 Groups of body heights

\begin{tabular}{|l|l|}
\hline The name of the group & Description \\
\hline Group S1 & $155<$ Ic $<160.9 \mathrm{~cm}$ \\
\hline Group S2 & $161<$ Ic $<166.9 \mathrm{~cm}$ \\
\hline Group S3 & $167<$ Ic $<172.9 \mathrm{~cm}$ \\
\hline Group S4 & $173<$ Ic $<178.9 \mathrm{~cm}$ \\
\hline Group S5 & $179<\mathrm{Ic}<184.9 \mathrm{~cm}$ \\
\hline Group S6 & $185<\mathrm{Ic}<191 \mathrm{~cm}$. \\
\hline
\end{tabular}

The age of the subject has a major influence on the shape of their body (stature). (fig. 2).

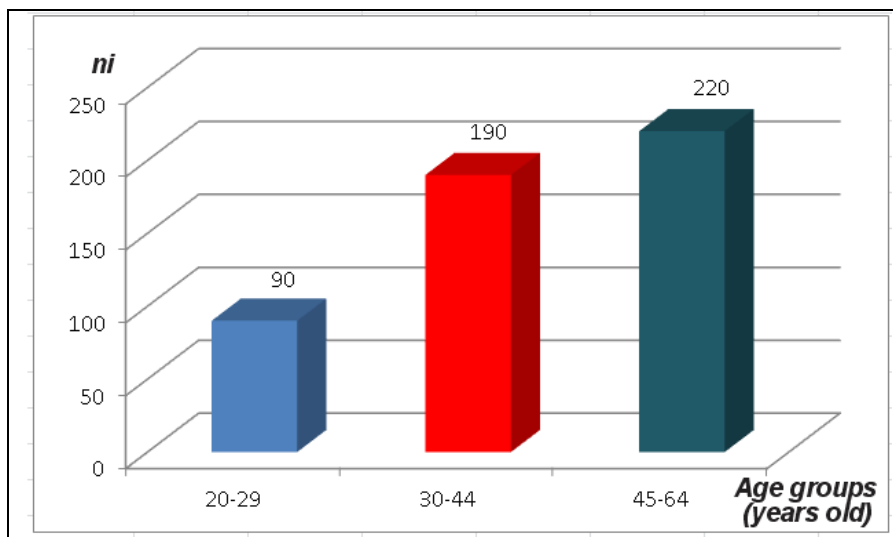

Fig 2. The absolute meeting frequency /age groups

Figure 2 shows that the third age group contains the largest numbers of subjects, surpassing the second one by a small margin (30 subjects) and that the first group contains the smallest number of subjects.

The persons who belong to the second group are physically mature, with professional careers, whereas the subjects from the first group have not reached maturity. The persons from the third group are still reliable for the purpose of the paper because they are physically mature, and their bodies are not yet starting to undergo changes due to the ageing process (they are not retired). Thus, over $80 \%$ of the subjects are reliable for this study, whose purpose is to characterise the posture among the adult male population.

\section{DETERMINING STATISTICAL PARAMETERS ASSOCIATED WITH THE MEASURED BODY DIMENSIONS}

The particular data for the aforementioned dimensions (see table 1 and fig 1), and the values obtained for the anthropometrical parameters have been statistically analysed by using the unidimensional analysis algorithm found in the Excel environment.

The following statistical parameters were determined: -the average value $\rightarrow \bar{x}(\mathrm{~cm})$

-the amplitude $\rightarrow \mathrm{A}(\mathrm{cm})$

-the variance of the selection $\rightarrow S_{x}^{2}\left(\mathrm{~cm}^{2}\right)$

-the standard deviation $\rightarrow S_{x}(\mathrm{~cm})$

-the variation coefficient $\rightarrow V_{x}(\%)$

-the standard deviation of the average value $\rightarrow S_{\bar{x}}(\mathrm{~cm})$

-the likely error value of the average value $\rightarrow \mathrm{e}_{\mathrm{M}}(\%)$

Table 3 centralises the average values of the measured body dimensions and $\mathrm{d}\left(\mathrm{P}_{\mathrm{cv}}-\mathrm{P}_{\mathrm{bg}}\right)$.

Table 4 shows the values of the statistical parameters associated the body dimensions and $\mathrm{d}\left(\mathrm{P}_{\mathrm{cv}}-\mathrm{P}_{\mathrm{bg}}\right)$.

Table 5 shows the average values of the posture parameters for the whole sample and for each group of heights.

TABLE 3 The average values of the anthropometric dimensions and indicators, calculated for each group of body heights criteria and for the whole sample $(\bar{x}(\mathrm{~cm}))$

\begin{tabular}{|l|c|c|c|c|c|c|c|}
\hline $\begin{array}{l}\text { Anth.dim/ } \\
\text { Anth } \\
\text { indicator }\end{array}$ & S1 & S2 & S3 & S4 & S5 & S6 & S \\
\hline $\mathrm{L}_{\mathrm{t}}$ & 41.6 & 42.9 & 43.6 & 44.9 & 45.5 & 45.8 & 43.9 \\
\hline $\mathrm{L}_{\mathrm{ft}}$ & 50.5 & 50.8 & 51.2 & 52.9 & 53.5 & 54.2 & 51.9 \\
\hline $\mathrm{A}_{\mathrm{vt}}$ & 85.8 & 87.1 & 88.5 & 90.2 & 92.9 & 94.2 & 89.1 \\
\hline $\mathrm{A}_{\mathrm{vs}}$ & 43.7 & 44.9 & 45.7 & 46.9 & 47.8 & 47.8 & 45.9 \\
\hline $\mathrm{ARF}$ & 29.4 & 30.1 & 30.3 & 30.9 & 31.6 & 32.8 & 30.5 \\
\hline $\mathrm{ARS}$ & 20.1 & 20.7 & 21.8 & 21.2 & 21.3 & 22.9 & 20.9 \\
\hline $\mathrm{m} 1$ & 9.54 & 9.5 & 9.52 & 9.82 & 10.1 & 10.3 & 9.66 \\
\hline
\end{tabular}

TABLE 4 Values of the main statistical parameters (whole sample)

\begin{tabular}{|l|l|l|l|r|r|r|}
\hline $\begin{array}{l}\text { Anth.dim/ } \\
\text { Anth } \\
\text { indicator }\end{array}$ & $\begin{array}{l}\mathbf{A} \\
\mathbf{( c m})\end{array}$ & \multicolumn{1}{|c|}{$\begin{array}{c}\boldsymbol{S}_{\boldsymbol{x}}^{\mathbf{2}} \\
\left(\mathbf{c m}^{\mathbf{2}}\right)\end{array}$} & $\begin{array}{l}\boldsymbol{S}_{\boldsymbol{x}} \\
(\mathbf{c m})\end{array}$ & \multicolumn{1}{c|}{$\begin{array}{l}\boldsymbol{V}_{\boldsymbol{x}} \\
(\boldsymbol{\%})\end{array}$} & $\begin{array}{c}\boldsymbol{S}_{\overline{\boldsymbol{x}}} \\
(\mathbf{c m})\end{array}$ & $\begin{array}{c}\boldsymbol{e}_{\boldsymbol{M}} \\
(\mathbf{c m})\end{array}$ \\
\hline $\mathrm{L}_{\mathrm{t}}$ & 17.5 & 8 & 2.8 & 6.38 & 0.125 & 0.285 \\
\hline $\mathrm{L}_{\mathrm{ft}}$ & 13 & 6.4 & 2.5 & 4.82 & 0.112 & 0.215 \\
\hline $\mathrm{A}_{\mathrm{vt}}$ & 20.5 & 24.7 & 4.97 & 5.58 & 0.222 & 0.249 \\
\hline $\mathrm{A}_{\mathrm{vs}}$ & 17 & 12.6 & 3.6 & 7.84 & 0.161 & 0.351 \\
\hline $\mathrm{ARF}$ & 10.5 & 4.24 & 2.1 & 6.89 & 0.094 & 0.308 \\
\hline $\mathrm{ARS}$ & 10 & 3.7 & 1.92 & 9.19 & 0.086 & 0.411 \\
\hline $\mathrm{m} 1$ & 6.5 & 14.7 & 3.14 & 32.51 & 0.140 & 1.454 \\
\hline
\end{tabular}

TABLE 5 The average values of the body posture parameters $(\bar{x}(\mathrm{~cm}))$

\begin{tabular}{|l|l|l|l|l|l|l|l|}
\hline $\begin{array}{l}\text { Body } \\
\text { posture } \\
\text { index }\end{array}$ & S1 & S2 & S3 & S4 & S5 & S6 & S \\
\hline $\mathrm{d}_{1}$ & -0.33 & -0.67 & -0.68 & -1.21 & -0.61 & 0.06 & -0.58 \\
\hline $\mathrm{d}_{2}$ & -0.704 & -1.45 & -1.53 & -1.78 & -1.66 & -0.97 & -1.34 \\
\hline $\mathrm{d}_{3}$ & -0.33 & -0.04 & 0.11 & -0.24 & 0.13 & -0.15 & -0.1 \\
\hline $\mathrm{i}_{\mathrm{u}}$ & 3.98 & 4.4 & 4.3 & 4.6 & 4.5 & 4.8 & 4.25 \\
\hline $\mathrm{i}_{\mathrm{u}}$, & 5.5 & 5.7 & 5.6 & 6.12 & 5.8 & 6.7 & 5.9 \\
\hline
\end{tabular}

By interpreting the results (the values of the statistic parameters from tables, 3,4 and 5), the designer can obtain data that is useful in determining the optimal size and shape of the patterns of the pieces from the garment structure. [4] 
IV. INTERPRETATION OF THE RESULTS AND CONCLUSIONS

The results from table 3 lead to the following conclusions: -as expected, when the height increases, the values of all the anthropometric dimensions measured on the trunk have the same tendency;

-the anthropometric dimensions measured on the backside of the trunk have a slightly higher rate of change than the ones measured on the front side $\rightarrow$ the scapula points and curves of the spine line are more pronounced than the prominence of the bust. Besides this, the extent of the muscular contraction is less significant than scapular prominences (the body measurements were taken in the normal orthostatic position, which means that the muscles of the back were relaxed);

-the values of the increments of ARF and ARS, measured for successive height groups, lend evidence to the aforementioned idea regarding the differences registered in the upper part of the trunk (above the bust line) when compared to the portion between the bust line and the waistline;

-the neck change (transversal direction) is not influenced by the height of the body;

-after analysing the average values for groups S1-S6 and the value for the whole sample $(\mathrm{S})$, we can conclude that the value of the whole sample is closest to the one registered for $\mathrm{S} 3$. This means that there are relatively many subjects (an important percentage from the total) whose height fits into this group. This is true for all the body measurements, with two exceptions, $\mathrm{A}_{\mathrm{vt}}$ and ARS.

By analysing the information from table 4 , we reach the following conclusions:

-for all body measurements, the average values $(\bar{x})$ are representative from a statistical point of view because the values of $\mathbf{e}_{\mathbf{m}}$ are smaller than $5 \%$.

-As the values of $\mathbf{e}_{\mathbf{m}}$ are below $1 \%$, we can also say that the average values of all body dimensions have the highest level of representativity.

Under these circumstances, we can infer that the $(\bar{x})$ statistic parameter is a good estimator of the true mean of the population. Thus, the conclusions obtained by interpreting the statistic parameters of the selection are also valid for the whole population.

-the amplitude value of $\mathrm{L}_{\mathrm{t}}$ is larger than the one of $\mathrm{L}_{\mathrm{tf}}$; in this sample, there are persons who have close values for $\mathrm{L}_{\mathrm{tf}}$ and different values for the $\mathrm{L}_{\mathrm{t}}$. This can also be noticed for the amplitude values of $\mathrm{A}_{\mathrm{vt}}$.

-the amplitude value of "m1" is the smallest one; in the sample, the subjects have similar shapes of the neck area;

-the values of $V_{x}$ are generally less than $10 \%$; there is one exception, namely the one of " $\mathrm{m} 1$ ".

Doctors and anthropologists usually classify the values of $V_{x}$ by taking into account some intervals. If the latter is less than $10 \%$, then one says that the selection has the highest degree of homogeneity; if the value of $V_{x}$ is in the $(10 \div 20) \%$ range, the homogeneity degree is considered to be medium, whereas, for a value greater than $20 \%$, the homogeneity degree is regarded as low. [1].

The value of $V_{x}$ for " $\mathrm{m} 1$ " indicates that the particular values of the sample are spread over a wide range, and with significant deviations from the average value. This means that the shape of the neck varies significantly among the persons from the sample, even if the rest of their trunks are similar.

The $V_{x}$ value of ARS is another interesting parameter because it is very close to the 10\%-threshold; There are persons in the selection with different shapes and size of the backside.

The average values of the body posture parameters (table5) lead to important conclusions regarding the shape of the trunk and the way in which the posture and the height of the body influence each other.

- it is very important to have a good model of the shape of the upper part of the trunk because it is the area where the garments supported on shoulders must fit very well.

The area around the neck, the shoulder line, up until the middle level of the breastbone (front side) and of the scapula blade (backside), the garment has to fit in an optimal position (well balanced). If this condition is not satisfied, then the garment will move towards the front or back, or it will exert an abnormal amount of pressure on the body.

-the curves of the backside and the shape of the front side determine negative values for $\mathrm{d} 1, \mathrm{~d} 2$ and $\mathrm{d} 3$ (posture parameters). The heights of the bodies influence the values of all of the aforementioned parameters. The largest values for $\mathrm{d} 1$ and $\mathrm{d} 2$ are exhibited by group $\mathrm{S} 4$, whereas the largest values for $\mathrm{d} 3$ have been recorded for group S1. A noteworthy phenomenon is exhibited by groups S5 and S6, where $\mathrm{d} 3$ has a small and positive value. Thus, for these height groups, the front side of the trunk is well developed when compared to the backside.

-the parameters that describe the shoulder position have positive values for each group of heights and for the whole selection.

The values of " $i_{u}$ " tend to increase with height. To be more specific, they increase up until group S4, but decrease from S4 to S5, before increasing from S5 to S6. Thus, we can conclude that the selection consists of subjects with various shapes of the spine line (as we have already noted), which in turn influences the position of the cervical point.

By taking into account all of these aspects, the designer will be able to develop a suitable and well-fitted model of garments with support on shoulders, perfectly adapted to the shape of the customer's body.

Provided that the designer enters in possession of the customer's scanned virtual body, they will be able to select, use and determine different anthropometric dimensions and posture parameters, which are key to obtaining a wellbalanced customised product.

By using the customer's virtual image, and by employing proper 3D CAD instruments, the designer will be able to create the virtual prototype of the chosen model and to simulate dressing the body in order to evaluate its fitting degree. In this manner, the designer obtains a virtual prototype that can be used to validate the adopted design solution.

The study of posture parameters can be extended; using statistical analyse, the primary data of the male body posture 
can be used to define the representative postures of the Romanian male subjects, after age and body heights criteria.

Besides determining the values of the posture parameters, it is also important to know how to analyse the conformation and proportions of the body, in order to be able to adapt the production to all of the demands of the national and international customers and markets.

\section{REFERENCES}

[1] Brumariu, A., Mitu, S., Filipescu, E., Avădanei, M., etc.,-- Proiectarea constructivă a produselor de îmbrăcăminte, cap. VII.5, în Manualul inginerului textilist, vol. II, partea B, Lucrare editată de Ministerul Educaţiei, Cercetării şi Tineretului, Banca Comercială Română, 2003, ISBN 973-8466-10-5, ISBN 973-8466-96-2, pag. 783-1044

[2] Bourdieu, Pierre, 'Haute couture and haute culture,' in Sociology in Question. Sage.., https://en.wikipedia.org/wiki/Fashion).

[3] Kobliakva E.B., Knstruirovanie odejdi s elementami SAPR, Leggprombitizdat, Moscow, 1988

[4] Taloi D.,"Optimizarea proceselor metalurgice", Ed. didactică şi pedagogică, Bucuresti, 1983.

[5] *** SR 13544. Îmbrăcăminte. Dimensiunile corpurilor şi mărimi de confecţii pentru bărbaţi

[6] *** STAS 5279-85. Imbracaminte. Masurarea corpului omenesc. 